\title{
Epidemiology of cutaneous leishmaniasis in a newly emerging focus in Gampaha district, Western province of Sri Lanka
}

Chandana Harendra Mallawarachchi

Medical Research Institute

Nilmini T. G. A. N Chandrasena ( $D$ nilminicha64@gmail.com )

https://orcid.org/0000-0002-2010-7636

Tharaka Wijerathna

University of Kelaniya Faculty of Medicine

Rasika C.P.D. Dalpadado

The Office of the Regional Director of Health Service, Gampaha

Maleesha S.M.N.S. Mallawarachchi

Ministry of Health

Gunarathna G.A.M.D

Ministry of Plantation and Export Agriculture

Nayana Gunathilaka

University of Kelaniya Faculty of Medicine

\section{Research Article}

Keywords: Cutaneous Leishmaniasis, emerging, Sri Lanka, Gampaha

Posted Date: May 18th, 2020

DOl: https://doi.org/10.21203/rs.3.rs-28735/v1

License: (c) (i) This work is licensed under a Creative Commons Attribution 4.0 International License.

Read Full License 


\section{Abstract}

Background Cutaneous leishmaniasis (CL) appears to be spreading to previously non-endemic regions of Sri Lanka. The aim of this study was to describe a newly emerging focus of CL in the district of Gampaha, in Western Sri Lanka. Methods A case based descriptive study was carried out from January 2018 to April 2019 in the Mirigama Medical Officer of Health (MOH) area, which reported the highest number of $\mathrm{CL}$ cases in Gampaha District. Laboratory confirmed cases were traced and sociodemographic and clinical data were collected via a validated questionnaire and clinic records respectively. The quality of life (QOL) of study participants was measured using the Dermatology Life Quality Index (DLQI). Global Positioning System (GPS) coordinates of patient residences were recorded using handheld GPS receivers. Sand-flies were collected from four selected sites, using Indoor Hand Collection (IHC) (162 units) and Cattle Baited Net Traps (CBNT) $(n=3)$ and a battery-operated aspirator. Results Of 73 patients identified in this study, $58.9 \%$ were males, with a mean age of 43.6 years (SD 20.1). The lesions included nodules (52.05\%) and ulcers (47.9\%). Single lesions were seen in $69.86 \%$, while $30.1 \%$ had multiple. Except for one mucosal lesion, all others were on skin. Treatment varied from sodium stibogluconate (SSG) + cryotherapy (46.57\%), SSG (45.2\%) and cryotherapy (8.2\%). Patients with multiple lesions were more likely to be treated with combined SSG + cryotherapy $(p<0.05)$. The mean DLQI score was $8.14(S D=7)$. Most patients engaged in outdoor activities that exposed them to the risk of sand-fly bites Workplaces of $81.1 \%$ (27/33) were located within the district. Housing conditions of study participants were of moderate (59\%), good (35.6\%) and poor (5\%) quality. Four households reported multiple cases. Spatial distribution of cases indicated notable clustering in seven adjacently located Public Health Inspector (PHI) areas. Phlebotomus argentipes was detected in all CBNTs and $35.28 \%$ of $\mathrm{IHC}$ units surveyed. Conclusions $\mathrm{CL}$ is emerging in Gamapha district with Mirigama $\mathrm{MOH}$ area being the epicentre of infection. The disease had a moderately negative impact on QOL of patients. Minimal migration of cases, clustering of cases within households and in the locality indicates local transmission with P. argentipes as the probable vector.

\section{Background}

The leishmaniosis are a group of vector-borne infections caused by protozoan flagellates of genus Leishmania. These infections are transmitted by female phlebotomine sand-flies and numerous mammalian species including humans are affected. Over 20 species of Leishmania have been implicated in human disease $[1,2]$ of which the majority are zoonotic parasites [3].

Leishmaniases are widespread in the tropics, subtropics and temperate regions of the world, threatening people in 98 countries which include 72 developing countries [4]. As the less affluent populations in Africa, Asia and Latin America are mainly affected, leishmaniases are categorized as neglected tropical diseases. The three main clinical forms of diseases are cutaneous (CL), visceral (VL) and mucocutaneous (MCL) leishmaniasis. The geographical distribution of disease phenotypes overlaps considerably: 68 countries are endemic for both $\mathrm{VL}$ and $\mathrm{CL}$, while a few countries are endemic only for 
one type ( 21 endemic for $\mathrm{CL}$ and nine for $\mathrm{VL}$ ). The cutaneous form of the disease accounts for $50-75 \%$ of the estimated two million cases of leishmaniases that exist worldwide [5].

Sri Lanka is endemic for CL. Since the first indigenous case was reported in 1992 from the Southern Province of Sri Lanka [6], the case numbers have steadily risen with geographical expansion to include North-Central, Northern and North-Western provinces of the country [7, 8]. In response to this situation, Sri Lanka declared CL a notifiable disease in 2008. The causative agent of CL in Sri Lanka was identified as L. donovani zymodeme MON 37, a genetic variant of the visceralising species $L$. donovani [9]. A few indigenous cases of $V L$ and $M C L$ caused by the same parasite have been also reported subsequently [10-12].

A total of 22 species of sand-flies have been recorded from Sri Lanka since 1910's [13]. Vector studies in endemic regions of the country implicate Phlebotomus argentipes as the most probable vector in Sri Lanka [14-17]. It is considered as a species complex composed of three sibling species [18]: namely, $P$. argentipes glaucus, $P$. argentipes sensu stricto and $P$. argentipes annadalei. All three members of the $P$. argentipes species complex have been reported in Northern Sri Lanka [19], while $P$. argentipes var. glaucus has been widely reported elsewhere (Central, Southern, and Northwestern provinces) $[15,20]$. Although dogs, cattle and rats are known to harbor L. donovani [21-23], a zoonotic reservoir host has not been properly characterized from Sri Lanka.

Although cases of $C L$ have been documented throughout the country, the large majority (over $90 \%$ ) is usually from the North Central, North Western and Southern provinces [24]. A very low number of cases have been identified in the Western province, which includes Colombo, Gampaha and Kalutara districts [24]. Thus, $C L$ was an infrequent infection in the district of Gampaha until recently. However, during the past two years, an increasing number of cases were referred for diagnosis to the Department of Parasitology, Faculty of Medicine, University of Kelaniya, in Ragama, Sri Lanka. Analysis of the weekly epidemiological reports published by the Ministry of Health, Sri Lanka indicated a tenfold rise of cases in the district of Gampaha from 2018 onwards (68 cases in 2018 compared to seven in 2017) [25].

The rapid expansion of case numbers in a hitherto non-endemic area required an in-depth investigation. Hence, the objective of the present study was to describe the disease epidemiology and the impact of CL on life quality among patients in a newly emerging focus of $C L$ in the district of Gampaha in Western Sri Lanka.

\section{Methods}

\section{Study area}

The district of Gampaha is semi-urban, extending over an area of $1,387 \mathrm{~km} 2$ located between $6054.5 \rrbracket$ and $7020.0 \otimes$ Northern latitude and between $79048.75 \rrbracket$ and $80013.00 \otimes$ Eastern longitude. It has a tropical climate with a mean annual rainfall of $1,423 \mathrm{~mm}$, a mean annual temperature of $27.3 \mathrm{C}^{\circ}$ (range $22.7 \mathrm{C}^{\circ}-34.3^{\circ} \mathrm{C}$ ). The topography consists of three zones, low-lying flat lands at the coastal periphery, 
central in-land area with mild elevations ( $<100 \mathrm{~m}$ above sea level) and the eastern highlands which include a range of woody mountains (150-450 m above sea level) [26]. Over one third of land area $\left(499.94 \mathrm{~km}^{2}, 35.4 \%\right)$ is agricultural with paddy, coconut and rubber being the main crops. The proportion of forest cover including scrub vegetation is $1.97 \%$ (27.32 km2) [26]. Gampaha has a population density of $1,719 / \mathrm{km} 2$, making it the second most populous district in the country [26].

\section{Selection of study population}

The Gampaha district has $15 \mathrm{MOH}$ areas. The occurrence of leishmaniasis is not uniform in all $\mathrm{MOH}$ areas. Data on the leishmaniasis disease morbidity archived at the Regional Epidemiology Unit (REU) Gampaha, and published information by the Epidemiology Unit, Ministry of Health were retrospectively analyzed from January 2018 to April 2019 to identify the $\mathrm{MOH}$ area reporting the highest number of cases. It was found that more than half the cases were reported from Mirigama $\mathrm{MOH}$ area [27]. Therefore, Public Health Inspector (PHI) areas of Ambepussa, Banduragoda, Danowita, Kahatapitiya, Kal-Eliya, Mirigama and Weweldeniya of the Mirigama MOH was selected for the present study (Fig. 1).

\section{Collection of primary data}

The patient records of CL cases notified to the Mirigama MOH office from January 2018 to April 2019 were obtained from the $\mathrm{MOH}$ office. Laboratory confirmed $\mathrm{CL}$ cases were selected and basic contact information was obtained.

\section{Household survey}

A pre-tested structured questionnaire was administered to the patients. In patients less than 18 years, the parent or guardian was interviewed. The basic demographic information such as age in years, level of education, marital status, gender and the family size of the respondents were recorded. Socio-economic factors such as occupation and housing condition were recorded. Housing conditions were categorized as "poor", "moderate" and "good" based on roof, wall and floor characteristics. The houses having plastered cement walls with clay tile or asbestos roofs were categorized as "Good", while un-plastered brick walls with tiled or asbestos roofs were considered as "Moderate". All other types were grouped as "Poor" houses [28]. Clinic records available with the patient were referred for confirmation of responses given by patients in the recording of clinical features.

\section{Mapping of patient households}

The geographic location of the patient households was obtained from a handheld GPS receiver (Etrex10 Garmin) and the houses were mapped using ARCGIS software package (Version 10.3). A 3D analysis was performed using the $Z$ value. Digital elevation model (DEM) was prepared. Elevation profile was developed to find out the minimum and maximum elevation of the area. Variogram of the grid data was used to observe the behaviour of the contours. Kriging methodology in 3D tool was employed in constructing the variogram. Cross validation report was utilized in finalizing the identified contour 
distribution of the area. Finally, the gridding report was generated to exclude any analytical or arithmetical errors. Further, ecological characteristics of the residential environments of patients were documented.

\section{Quality of life of leishmaniasis patients}

The QOL of CL patients was assessed using the DLQI [29]. The DLQI consists of 10 questions covering six domains: symptoms and emotions, shopping and housework, leisure activities, work or study, personal relationships and treatment. Each response was scored from 0-3 $(0=$ not affected; $1=$ little affected; 2 = a lot affected; 3 = very much affected). The higher the score the greater the impairment of QOL. The questions in DLQI questionnaire (English version) was translated to the native language, back translated to English to verify the accuracy of the translated version. The translated DLQI was administered by a trained research officer.

\section{Entomological investigation}

Entomological surveys were conducted in four PHI areas within the Mirigama $\mathrm{MOH}$ area (Weweldeniya, Mirigama, Kal-Eliya and Banduragoda) from March - April 2019, using IHC and CBNT collection, according to the guidelines described by the World Health Organization. The selection of sites for entomological investigations was done in consultation with the Regional Entomologist, Gampaha District based on the availability of cases, occurrence of suitable breeding/ resting habitats and environmental characteristic favourable for sand-flies.

Sand-flies were collected using a battery-operated aspirator and a killing jar with $70 \%$ chloroform. The killed samples were preserved in $25 \mathrm{ml}$ falcon tubes containing $70 \% \mathrm{v} / \mathrm{v}$ ethanol solution and transferred to the laboratory at the Department of Parasitology, Faculty of Medicine, University of Kelaniya, Sri Lanka for identification. The distal part of abdomens and entire heads of sand-flies were dissected using fine needles and macerated using 10\% lactophenol for 1-2 hours. Cleared insect parts were mounted in Berlese medium and identified using morphological taxonomic keys [30, 31].

\section{Data tabulation and analysis}

The collected data were entered to EpiData (JM Lauritsen, Version 4.4.3.1) data handling software package. The percentages mean and standard deviation values were calculated in MS Excel (Microsoft, USA). The ARCGIS software package (version 10.3) was used for spatial analysis.

\section{Results}

\section{Clinical presentation of patients and treatments}

Sixty-two cases of CL were notified to the REU Gampaha during the study period. Eleven more confirmed cases (non-notified) detected during field-visits were also included in the study population. Of the total 73 cases of $C L, 58.9 \%(n=43)$ were males. The mean age of the study population was 43.6 years. Lesions of varying stages (acute, healing and healed) were seen with sizes varying from $3 \mathrm{~mm}-40 \mathrm{~mm}$ and included nodules $(52.1 \%, \mathrm{n}=38)$, dry ulcers $(47.9 \%, \mathrm{n}=34)$ and one wet mucosal ulcer. Almost all $(97.3 \%$, 
$n=71)$ were located on exposed body regions. Single lesions were seen in $69.9 \%(n=51)$, while $30.1 \%(n$ $=22$ ) had multiple lesions.

Treatment received at dermatology clinics of the state medical institutions varied from SSG $(45.2 \%, n=$ $33)$, SSG combined with cryotherapy $(46.57 \%, n=34)$, or only cryotherapy $(8.2 \%, n=6)$. Those with multiple lesions were significantly more likely to have received SSG combined with cryotherapy $(P<0.05)$.

\section{Quality of life assessment in patients}

Only 29 study participants responded to all the questions in the DLQI questionnaire. The DLQI scores ranged from $0-23$ with a mean score of $8.14(S D=7)$. The domains that were most affected were those related to emotions (shame and embarrassment) and shopping and household work.

\section{Socio-economic and demographic factors}

Among the employed $(33,45.2 \%)$, majority were casual labourers $(n=16 ; 48.5 \%)$, followed by indoor based skilled workers $(n=7 ; 21.2 \%)$, farmers $(n=6 ; 18.2 \%)$ and drivers $(n=4 ; 2.2 \%)$. The unemployed $(54.7 \%)$ were housewives $(n=24,60 \%)$, followed by school students $(n=13 ; 32.5 \%)$ and pensioners $(n=3$; $7.5 \%)$. The majority of the employed patients $(n=27 ; 81.8 \%)$ had their workplaces located within the district of Gampaha. Most were engaged in outdoor activities that exposed them to the risk of sand-fly bites. The houses of most patients $(n=43 ; 58.9 \%)$ were of moderate quality, as shown in Table 01. The presence of poorly maintained walls with deficits (cracks and crumbling plaster) was noted in $64.38 \%$ ( $n$ $=47$ ). Animals (dogs, cattle, etc) in the peri-domestic area of residences were also noted

\section{Spatial distribution of cases}

Distribution of cases revealed clustering in seven of the nine PHI areas as documented in Table 2. 
Table 1

Demographic characteristics of CL patients in Mirigama $\mathrm{MOH}$ area.

\begin{tabular}{|lll|}
\hline Variable & Male & $\begin{array}{l}\text { Number of patients } \\
\text { (percentage) }\end{array}$ \\
\hline Gender. & Female & $43(58.90 \%)$ \\
\hline Age (Years): & $1-5$ & $30(41.10 \%)$ \\
& $6-19$ & $4(5.48 \%)$ \\
& $20-49$ & $10(13.70 \%)$ \\
\hline Education: & 50 years and above & $25(34.25 \%)$ \\
& No formal education & $34(46.58 \%)$ \\
& Primary school (grade 5 & $14(19.18 \%)$ \\
& completed) & $27(36.99 \%)$ \\
& Passed O/L & $18(24.66 \%)$ \\
& Passed A/L & $02(2.73 \%)$ \\
& Schooling & $11(15.07 \%)$ \\
\hline Meneral house Condition: & Pre-schooling & $01(1.37 \%)$ \\
\hline Duration of stay in the study & Poor & $56(76.71 \%)$ \\
\hline & Married & $17(23.29 \%)$ \\
\hline & Unmarried & $01(1.37 \%)$ \\
& Good & $72(98.63 \%)$ \\
\hline
\end{tabular}


Table 2

Distribution of $\mathrm{CL}$ patients in $\mathrm{PHI}$ areas belonging to the Mirigama MOH, 2018-2019

\begin{tabular}{|llllll|}
\hline PHI area & \multicolumn{2}{l}{ Notified } & \multicolumn{2}{c}{ Non-notified } & Total \\
\cline { 2 - 5 } & $\mathbf{2 0 1 8}$ & $\mathbf{2 0 1 9}$ & $\mathbf{2 0 1 8}$ & $\mathbf{2 0 1 9}$ & \\
\hline Ambepussa & 10 & 02 & 00 & 00 & 12 \\
\hline Banduragoda & 11 & 01 & 00 & 00 & 12 \\
\hline Danowita & 01 & 00 & 01 & 03 & 05 \\
\hline Kahatapitiya & 02 & 01 & 00 & 00 & 03 \\
\hline Kal-Eliya & 08 & 02 & 02 & 01 & 13 \\
\hline Mirigama & 06 & 05 & 00 & 02 & 13 \\
\hline Weweldeniya & 07 & 06 & 01 & 01 & 15 \\
\hline Total & $\mathbf{4 5}$ & $\mathbf{1 7}$ & $\mathbf{0 4}$ & $\mathbf{0 7}$ & $\mathbf{7 3}$ \\
\hline
\end{tabular}

The highest cases were recoded from Wewaldeniya, Migirama and Kal-Eliya PHI sites. It is important to note that there were some non- notified cases of $\mathrm{CL}$ were identified from some areas. These cases were detected based on the information received from the interviewed patients which had been notified to the Mirigama $\mathrm{MOH}$ office. The non-notified patients had been confirmed for $\mathrm{CL}$ both clinical and laboratory methods.

A map showing the topography and spatial distribution of patients' residences is shown in Fig. 2. Over half the residences $(57.53 \%, n=41)$ were located $100 \mathrm{~m}$ above sea level (hills of $100-165 \mathrm{~m}$ above sea level). Stone barriers were noted on most premises, constructed to stabilize steep inclines and control soil erosion. The peri-domestic areas of most patient settlements $(67.12 \% ; n=49)$ were shady due to the foliage of numerous large trees and rocks (medium sized) were noted in $(79.45 \% ; n=58$ ) household premises.

\section{Entomological data on vector prevalence}

Among the total of 102 sand-flies collected, $P$. argentipes was the predominant species, followed by unidentified Sergentomyia sp. (sub family Neophlebotomus) and Sergentomyia babu insularis. Overall, the CBNT technique was more productive for sand-fly collection with a density of 8 per trap, while IHC resulted in a density of 0.48 per house. Table 3 shows the number of sampling units and the number of sand-flies recorded from each type. The highest sand fly density for $\mathrm{HC}$ was recorded from Wewaldeniya (0.8) $\mathrm{PHI}$ area followed by Banduragoda (0.62), Mirigama (0.58) and Kal-eliya (0.12). 
Table 3

Sand-fly species encountered form different techniques.

\begin{tabular}{|c|c|c|c|c|}
\hline \multirow[t]{2}{*}{ Technique } & \multirow{2}{*}{$\begin{array}{l}\text { Sampling } \\
\text { Unit }\end{array}$} & \multirow{2}{*}{$\begin{array}{l}\text { Total units } \\
\text { performed }\end{array}$} & \multicolumn{2}{|l|}{ Sandflies collected } \\
\hline & & & Species & Number \\
\hline \multirow{3}{*}{$\begin{array}{l}\text { Indoor Hand } \\
\text { Collection }\end{array}$} & \multirow[t]{3}{*}{ Houses } & \multirow[t]{3}{*}{162} & Phlebotomus. argentipes & 50 \\
\hline & & & $\begin{array}{l}\text { Unidentified Sergentomyia } \\
\text { sp. }\end{array}$ & 25 \\
\hline & & & $\begin{array}{l}\text { Sergentomyia babu } \\
\text { insularis }\end{array}$ & 03 \\
\hline \multirow{2}{*}{$\begin{array}{l}\text { Cattle Baited Net } \\
\text { Trap }\end{array}$} & \multirow[t]{2}{*}{ Trap } & \multirow[t]{2}{*}{3} & Phlebotomus. argentipes & 21 \\
\hline & & & $\begin{array}{l}\text { Unidentified Sergentomyia } \\
\text { sp }\end{array}$ & 3 \\
\hline
\end{tabular}

\section{Discussion}

Our findings indicate that there is spatial expansion of CL transmission in Sri Lanka involving hitherto non-endemic regions in the wet zone of the country. The districts of Anuradhapura, and Polonnaruwa in the North Central province, and Hambantota in the Southern province of Sri Lanka were the initial hotspots of CL [24]. More recently (2014-2016), the district of Kurunegala in the North Western province has become a major hotspot for $\mathrm{CL}$ [24]. The current focus of infection in the district of Gampaha may have originated from the adjacent Kurunegala district or from a more distant focus due to patient migration. However, the majority of our study population had minimal travel to areas outside the district. Clustering of cases within the $\mathrm{MOH}$ area with multiple cases occurring within the same household is in support of established transmission within the locality with the possibility of peri-domestic or domestic transmission as reported in the Southern province [32].

Phlebotomus argentipes has been identified as a potential vector of CL in Sri Lanka [14-16]. The presence of $P$. argentipes in the Mirigama $\mathrm{MOH}$ area suggests that the same species may be responsible for transmission in the Western province as well. Further, the highest sand fly density in HC observed from Wewaldeniya $\mathrm{PHI}$ area which was detected to be the area with the highest number of cases confirmed that the availability of the vector is a contributing factor for disease occurrence. However, according to the World Health Organization guidelines for leishmaniasis vector incrimination [33,34], further studies on the presence of parasites within female sand flies, and evidence of luxuriant growth in the anterior midgut and on the stomodeal valve of the sand flies and experimental transmission using animal models are required for the incrimination of the exact vector species.

Similar to past reports, CL was found to affect a broad age range (2-77 years) and both genders with a slight adult male preponderance [35]. However, the recent disease trends of increased female and older adult involvement documented by Siriwardane et al., was noted [35]. Most of those affected were housewives, unskilled workers and school children who engaged in outdoor activities such as home 
gardening (housewives, unskilled workers and pensioners) and sports activities (school children). Even among the population categorized as indoor-based skilled workers (six), many reported involvements in agricultural activities after duty hours (afternoons and evenings) which coincided with the preferred biting time of the vector (dusk to dawn) [30].

The ecology of the current focus of $\mathrm{CL}$ is somewhat distinct from the previous endemic foci, which were located in the dry and intermediate climatic zones with abundant scrub forest cover. The current focus is in the wet zone of the country with an abundance of agricultural fields but minimal forest cover. However, wooded areas were observed on residual hills in the vicinity of most infected households. Galgamuwa et. al., reported that the highest incidence of $\mathrm{CL}$ was in lowlands $<100 \mathrm{~m}$ above sea level [18). In contrast over half the study participants (57.53\%) in Mirigama resided at altitudes $>100 \mathrm{~m}$ above sea level, on residual rocky hills. The presence of isolated rocks and stone barriers were also noted on most (17/32) of the residences located at lower elevations ( $<100 \mathrm{~m}$ above sea level).

During the day, sand-flies rest in dark, sheltered and humid but dry surfaces $[30,36,37]$ as they require protection from sunlight, wind and rain $[38,39]$. Moist microenvironments rich in humus are preferred for egg laying. Populations of sand-flies tend.to be localized as they do not disperse far from their breeding sites $[30,40]$. Thus the existence of breeding and resting places in very close proximity to human settlements facilitates the transmission of leishmaniasis [41]. The cracks and crevices in house walls, stone-barriers and rocky terrains in and around most patient residences perhaps provide suitable resting places while the wooded areas with rotting leaf litter may provide the humus rich microenvironment required for egg-laying. Poor housing conditions were reported as significant risk factors of $C L$ in southern Sri Lanka $[7,42]$. The houses of $64.38 \%$ in the current study were either of poor quality or poorly maintained and one third of houses screened were positive for $P$. argentipes indicating the possibility of domestic transmission. The significance of pets and livestock animals in the peri-domestic area is not known as zoonotic reservoir hosts are unknown.

The current report was based only on case analysis; thus the risk potential of ecological characteristics observed cannot be analyzed statistically for their significance. The study was limited to the Mirigama $\mathrm{MOH}$ area which reported the highest number of cases within the district of Gampaha. Thus the current observations may provide only a superficial glimpse of the $\mathrm{CL}$ situation in the Gampaha district and may not be reflective of the entire area affected. Vector studies require further in-depth investigations as to their breeding, resting and, feeding behaviors, insecticide susceptibility patterns and the vectorial capacity of the sand fly populations.

Although CL lesions may heal spontaneously, treatment is recommended to minimize scarring and the spread of disease. Most patients were managed with a course of intra-lesion SSG as per guidelines formulated by the Sri Lanka College of Dermatologist (SLCD 2012-14) while for more complicated lesions SSG combined with cryotherapy was administered.

The mean DLQI of 8.137 (range $0-23$ ) suggests that CL does have a moderate negative impact on the QOL of the current study population. This is in contrast to the mean DLQI of 3.18 (range $0-30$ ) reported 
by Refai et. al. [43] among civilian patients in Anuradhapura, but is somewhat comparable to the mean DLQI of 6.02 (males) reported by Ranawaka et. al. [44]. In agreement with Ranawake et. al., the most affected domains were emotions (feelings of shame and embarrassment) and shopping and household duties [44].

Early diagnosis and complete treatment, integrated vector management combined with disease surveillance and social mobilization are some of the recommended control strategies for leishmaniases $[33,45]$. Although disease surveillance is in place, deficiencies were noted as $15 \%(11 / 73)$ of cases were not notified. An integrated vector management strategy is yet to be implemented in $\mathrm{CL}$ endemic areas of Sri Lanka. At this point of time, a multi-pronged approach is urgently required to control the spread of $\mathrm{CL}$ which is threatening the entire country. Ensuring the availability of treatment even in non-endemic areas, implementation of vector control measures and creating awareness among medical professional as well as the community is important to combat the spread of infection.

\section{Conclusions}

The district of Gampaha is the most recent focus to be affected by $\mathrm{CL}$ in Sri Lanka with Mirigama MOH being the epicentre of infection. The disease had a moderately negative impact on life quality. Minimal migration of patients, clustering of cases within households and the locality, support local transmission, with $P$. argentipes as the probable vector. Provision of countrywide disease management facilities, raising community awareness and vector surveillance with in-depth vector studies is recommended to control this emerging public health threat and reach.

\section{Abbreviations}

CL: Cutaneous leishmaniasis, VL: Visceral leishmaniasis, MCL: Mucocutaneous leishmaniasis, MOH: Medical Officer of Health, QOL: quality of life, DLQI: Dermatology Life Quality Index, GPS: Global Positioning System, IHC: Indoor Hand Collection, CBNT: Cattle Baited Net Traps, PHI: Public Health Inspector, SSG: Sodium Stibogluconate

\section{Declarations}

\section{Ethics approval and consent to participate}

Ethical clearance for the study was obtained from the Ethics Review Committees of the Faculty of Medicine University of Kelaniya, Sri Lanka (Ref. No. P/204/12/2016). Informed written consent was obtained from all participants and one of the parent or gradient for less than 18 years old participants.

\section{Consent for publication}




\section{Availability of data and material}

The datasets analysed during the current study are available from the corresponding author on reasonable request.

\section{Competing interests}

The authors declare that they have no competing interests.

Funding: National Research Council, Sri Lanka (Grant No. NRC 16-142) for field activities, sharing consumables and for use of laboratory facilities developed from the grant at the Department of Parasitology, Faculty of Medicine, University of Kelaniya, Ragama, Sri Lanka.

\section{Authors contributions}

$\mathrm{CHM}, \mathrm{NC}$ and NG took part in the design and conception of the study. CHM and TW involved in data collection. CHM, SMNSM participated in drafting the manuscript. NG, RD and TW gathered and analysed entomological data. GAMDG involved in geospatial analysis. NC, NG revised manuscript critically for important intellectual content. All authors read and approved the final manuscript.

\section{Acknowledgements}

The authors wish to thank Prof. Nilanthi de Silva for reading and providing useful comments to improve the quality of the manuscript. Public Health Inspectors in $\mathrm{MOH}$, Mirigama for assistance in field works.

\section{References}

1. Maroli M, Feliciangeli MD, Bichaud L, Charrel RN, Gradoni L. Phlebotomine sandflies and the spreading of leishmaniases and other diseases of public health concern. Med Vet Entomol. 2013;27:123-47.

2. Akhoundi M, Kuhls K, Cannet A, Votýpka J, Marty P, Delaunay P, et al. A Historical Overview of the Classification, Evolution, and Dispersion of Leishmania Parasites and Sandflies. PLoS Negl Trop Dis. 2016;10:e0004349. 
3. Bryceson AD. Leishmaniasis. In: Cook GC, editor. Manson's Trop Dis. 20th ed. London: WB Saunders; 1996. pp. 1213-45.

4. Alvar J, Vélez ID, Bern C, Herrero M, Desjeux P, Cano J, et al. Leishmaniasis Worldwide and Global Estimates of Its Incidence. PLoS One. 2012;7:e35671.

5. WHO. Leshmaniasis. 2018 [cited 2020 Apr 8]. Available from: .

6. Athukorale DN, Seneviratne JK, Ihalamulla RL, Premaratne UN. Locally acquired cutaneous leishmaniasis in Sri Lanka. J Trop Med Hyg. 1992;95:432-3.

7. Siriwardana HVYD, Noyes HA, Beeching NJ, Chance ML, Karunaweera ND, Bates PA. Leishmania donovani and cutaneous leishmaniasis, Sri Lanka. Emerg Infect Dis. 2007;13:476-8.

8. Karunaweera ND. Leishmania donovani causing cutaneous leishmaniasis in Sri Lanka: a wolf in sheep's clothing? Trends Parasitol. 2009;25:458-63.

9. Karunaweera ND, Pratlong F, Siriwardane HVYD, Ihalamulla RL, Dedet JP. Sri Lankan cutaneous leishmaniasis is caused by Leishmania donovani zymodeme MON-37. Trans R Soc Trop Med Hyg. 2007;97:380-1.

10. Abeygunasekara PH, Costa YJ, Seneviratne N, Ratnatunga N, Wijesundera M de. S. Locally acquired visceral leishmaniasis in Sri Lanka. Ceylon Med J. 2007;52:30-1.

11. Rathnayake D, Ranawake RR, Sirimanna G, Siriwardhane Y, Karunaweera N, De Silva R. Co-infection of mucosal leishmaniasis and extra pulmonary tuberculosis in a patient with inherent immune deficiency. Int J Dermatol. 2010;49:549-51.

12. Siriwardana HVYD, Karunanayake P, Goonerathne L, Karunaweera ND. Emergence of visceral leishmaniasis in Sri Lanka: a newly established health threat. Pathog Glob Health. 2017;111:317-26.

13. Wijerathna T, Gunathilaka N. Phlebotomine sand flies (Psychodidae: Diptera) of Sri Lanka: a review on diversity, biology and bionomics. J Insect Biodivers. 2019;11:41-58.

14. Gajapathy K, Peiris LBS, Goodacre SL, Silva A, Jude PJ, Surendran SN. Molecular identification of potential leishmaniasis vector species within the Phlebotomus (Euphlebotomus) argentipes species complex in Sri Lanka. Parasit Vectors. 2013;6:302.

15. Senanayake SASC, Abeyewicreme W, Dotson EM, Karunaweera ND. Characteristics of Phlebotomine Sandflies in Selected Areas of Sri Lanka. Southeast Asian J Trop Med Public Health. 2015;46:9941004.

16. Wijerathna T, Gunathilaka N, Gunawardana K, Fujii Y, Gunasekara D. Molecular detection of Leishmania donovani parasites in wild caught Phlebotomus argentipes using a PCR assay and species abundance of sand flies (Diptera: Psychodidae) in Kuruneagala District; an endemic focus of cutaneous leishmaniasis in Sri Lanka. Int Conf Multidiscip Approaches. 2018. p. 48.

17. Wijerathna T, Gunathilaka N, Gunawardena K. Diversity and abundance of sand flies (Psychodidae: Phlebotominae) in three cutaneous leishmaniasis endemic areas in Kurunegala District. Perad Univ Int Res Sess 2017. 2017. p. 315-6. 
18. Ilango K. A Taxonomic Reassessment of the Phlebotomus argentipes Species Complex (Diptera: Psychodidae: Phlebotominae). J Med Entomol. 2010;47:1-15.

19. Gajapathy K, Jude PJ, Surendran SN. Morphometric and meristic characterization of Phlebotomus argentipes species complex in northern Sri Lanka: evidence for the presence of potential leishmaniasis. Trop Biomed. 2011;28:259-68.

20. Ranasinghe S, Maingon RDC, Bray DP, Ward RD, Udagedara C, Dissanayake M, et al. A morphologically distinct Phlebotomus argentipes population from active cutaneous leishmaniasis foci in central Sri Lanka. Mem Inst Oswaldo Cruz. 2012;107:402-9.

21. $10.1645 /$ GE-2288

Rosypal AC, Tripp S, Kinlaw C, Hailemariam S, Tidwell RR, Lindsay DS, et al. Surveillance for Antibodies to Leishmania spp. in Dogs from Sri Lanka. J Parasitol [Internet]. American Society of Parasitologists; 2010 [cited 2019 Jul 16];96:230-1. Available from:

http://www.bioone.org/doi/abs/10.1645/GE-2288.

22. Wijerathna T, Gunathilaka N, Gunawardena K, Fujii Y, Gunasekara D. Molecular detection of blood meal sources of wild caught, engorged sand flies (Psychodidae: Diptera) in Sri Lanka. 6th Int Conf Sri Lanka Japan Collab Res 2018. Kandy; 2018. p. 4.

23. Nawaratna SSK, Weilgama DJ, Rajapaksha K. Cutaneous leishmaniasis in Sri Lanka: a study of possible animal reservoirs. Int J Infect Dis. 2009;13:513-7.

24. Galgamuwa LS, Dharmaratne SD, Iddawela D. Leishmaniasis in Sri Lanka: spatial distribution and seasonal variations from 2009 to 2016. Parasit Vectors [Internet]. 2018 [cited 2019 Apr 22];11:60. Available from: http://www.ncbi.nlm.nih.gov/pubmed/29370864.

25. Epidemiology Unit Epidemiology Unit. Weekly Epidemiology R. 2019 [cited 2019 Oct 10]. Available from: http://www.epid.gov.lk/web/index.php? option=com_content\&view=article\&id=148\&ltemid=449\&lang=en.

26. Department of Census Statistics. District Statistical Hand Book. Department of Census \& Statistics Sri Lanka; 2019.

27. Mallawarachchi $\mathrm{CH}$, Gunathilaka PADHN, Wijerathna T, Lahiru NWBAL, Mallawarachchi SMNSM, Chandrasena TGAN. A preliminary report on a newly emerging focus of cutaneous leishmaniasis in Gampaha district, Sri Lanka. Proc Int Conf Heal Sci 2019 Fac Med Sci Univ Sri Jayewardenepura. 2019. p. 101.

28. Gunathilaka N, Abeyewickreme W, Hapugoda M, Wickremasinghe R. Determination of demographic, epidemiological, and socio.economic determinants and their potential impact on Malaria transmission in Mannar and Trincomalee districts of Sri Lanka. Malar J. 2016;15:330.

29. Finlay AY, Khan GK. Dermatology Life Quality Index (DLQI)-a simple practical measure for routine clinical use. Clin Exp Dermatol. 1994;19:210-6.

30. Kalra NL, Bang YH. Manual on Entomology in Visceral Leishmaniasis. 1st ed. New Delhi: World Health Organization; 1988. 
31. Lewis DJ. The phlebotomine sandflies (Diptera: Psychodidae) of the Oriental Region. Bull $\mathrm{Br}$ Museum (Natural Hist Entomol Ser. 1978;37:217-343.

32. Kariyawasam KKGDUL, Selvapandiyan A, Siriwardana HVYD, Dude A, Karunanayake P, Senanayake SASC, et al. Dermotropic Leishmania donovani in Sri Lanka: visceralizing potential in clinical and preclinical studies. Parasitology. 2018;145:443-52.

33. WHO. Control of the leishmaniasis. Report of a meeting of the WHO Expert Committee on the Control of Leishmaniases. Geneva; 2010.

34. 10.1146/annurev-ento-120811-153557

Ready PD. Biology of Phlebotomine Sand Flies as Vectors of Disease Agents. Annu Rev Entomol. Annual Reviews; 2013 [cited 2017 Apr 27];58:227-50. Available from:

http://www.annualreviews.org/doi/10.1146/annurev-ento-120811-153557.

35. Siriwardana Y, Zhou G, Deepachandi B, Akarawita J, Wickremarathne C, Warnasuriya W, et al. Trends in Recently Emerged Leishmania donovani Induced Cutaneous Leishmaniasis, Sri Lanka, for the First 13 Years. BioMed Res Int. 2019 Apr 14;2019:1-11.

36. Hogsette JA, Hanafi HA, Bernier UR, Kline DL, Fawaz EY, Furman BD, et al. Discovery of Diurnal Resting Sites of Phlebotomine Sand Flies in a Village in Southern Egypt. J Am Mosq Control Assoc. 2008;24:601-3.

37. Chaniotis BN, Tesh RB, Correa MA, Johnson KM. Diurnal Resting Sites of Phlebotomine Sand flies in a Panamanian Tropical Forest. J Med Entomol. 1972;9:91-8.

38. Picado A, Das ML, Kumar V, Dinesh DS, Rijal S, Singh SP, et al. Phlebotomus argentipes seasonal patterns in India and Nepal. J Med Entomol. 2010;47:283-6.

39. Bern C, Hightower AW, Chowdhury R, Ali M, Amann J, Wagatsuma Y, et al. Risk factors for kala-azar in Bangladesh. Emerg Infect Dis. 2005;11:655-62.

40. Belen A, Alten B, Aytekin AM. Altitudinal variation in morphometric and molecular characteristics of Phlebotomus papatasi populations. Med Vet Entomol. 2004;18:343-50.

41. Bhunia GS, Kesari S, Jeyaram A, Kumar V, Das P. Influence of topography on the endemicity of Kalaazar: A study based on remote sensing and geographical information system. Geospat Health. 2010;4:155-65.

42. Rajapaksa US, Ihalamulla RL, Udagedera C, Karunaweera ND. Cutaneous leishmaniasis in southern Sri Lanka. Trans R Soc Trop Med Hyg. 2007;101:799-803.

43. Refai WF, Madarasingha NP, Sumanasena B, Weerasingha S, Fernandopulle R, Karunaweera ND. Cutaneous leishmaniasis in Sri Lanka: effect on quality of life. Int J Dermatol. 2018;57:1442-6.

44. Ranawaka RR, Weerakoon HS, de Silva SH. The quality of life of Sri Lankan patients with cutaneous leishmaniasis. Mymensingh Med J. 2014;23:345-51.

45. Le Rutte EA, Chapman LAC, Coffeng LE, Jervis S, Hasker EC, Dwivedi S, et al. Elimination of visceral leishmaniasis in the Indian subcontinent: a comparison of predictions from three transmission models. Epidemics. 2017;18:67-80. 
Figures

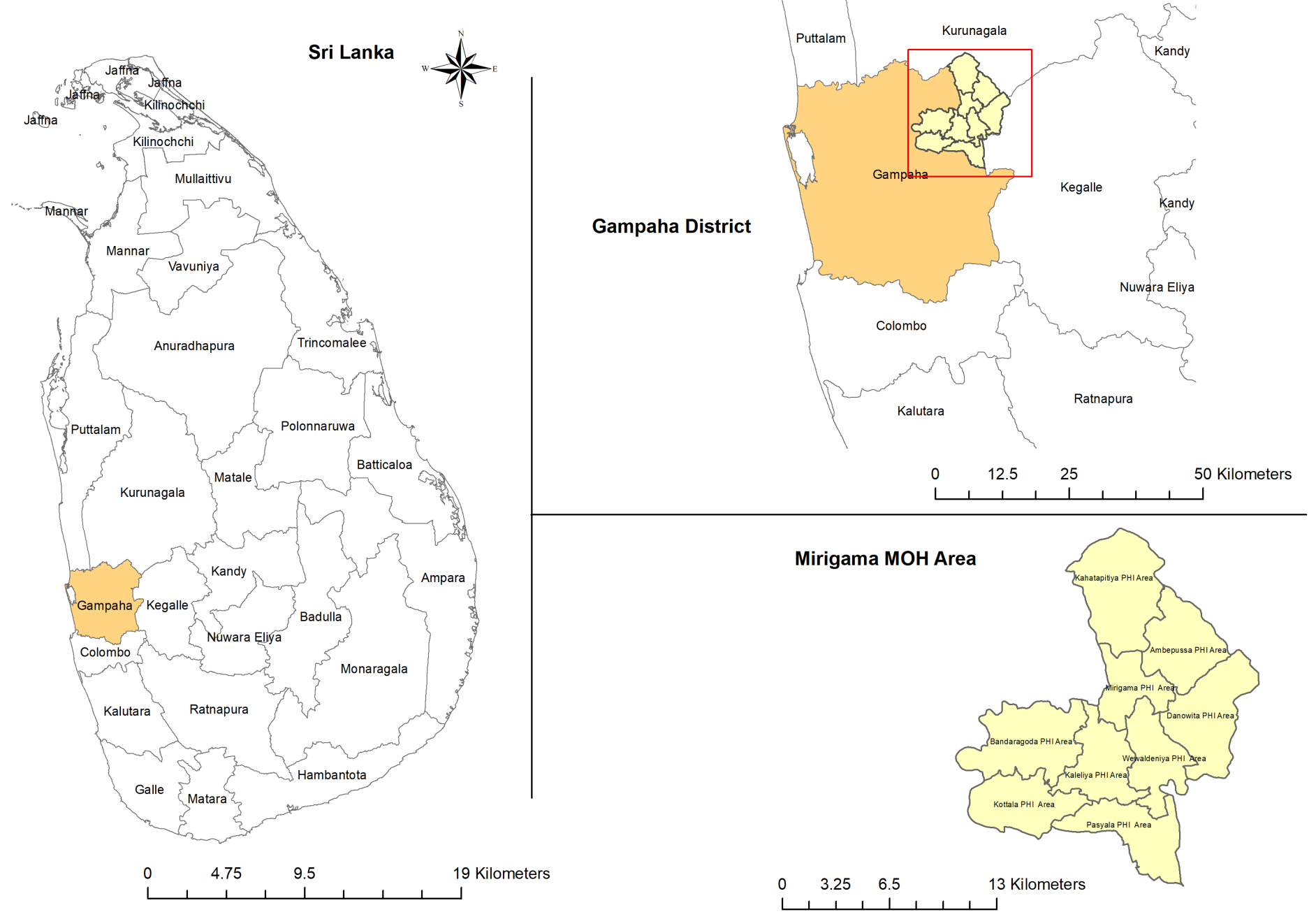

\section{Figure 1}

District map of Sri Lanka depicting newly emerging focus of leishmaniasis study area indicating PHI areas 


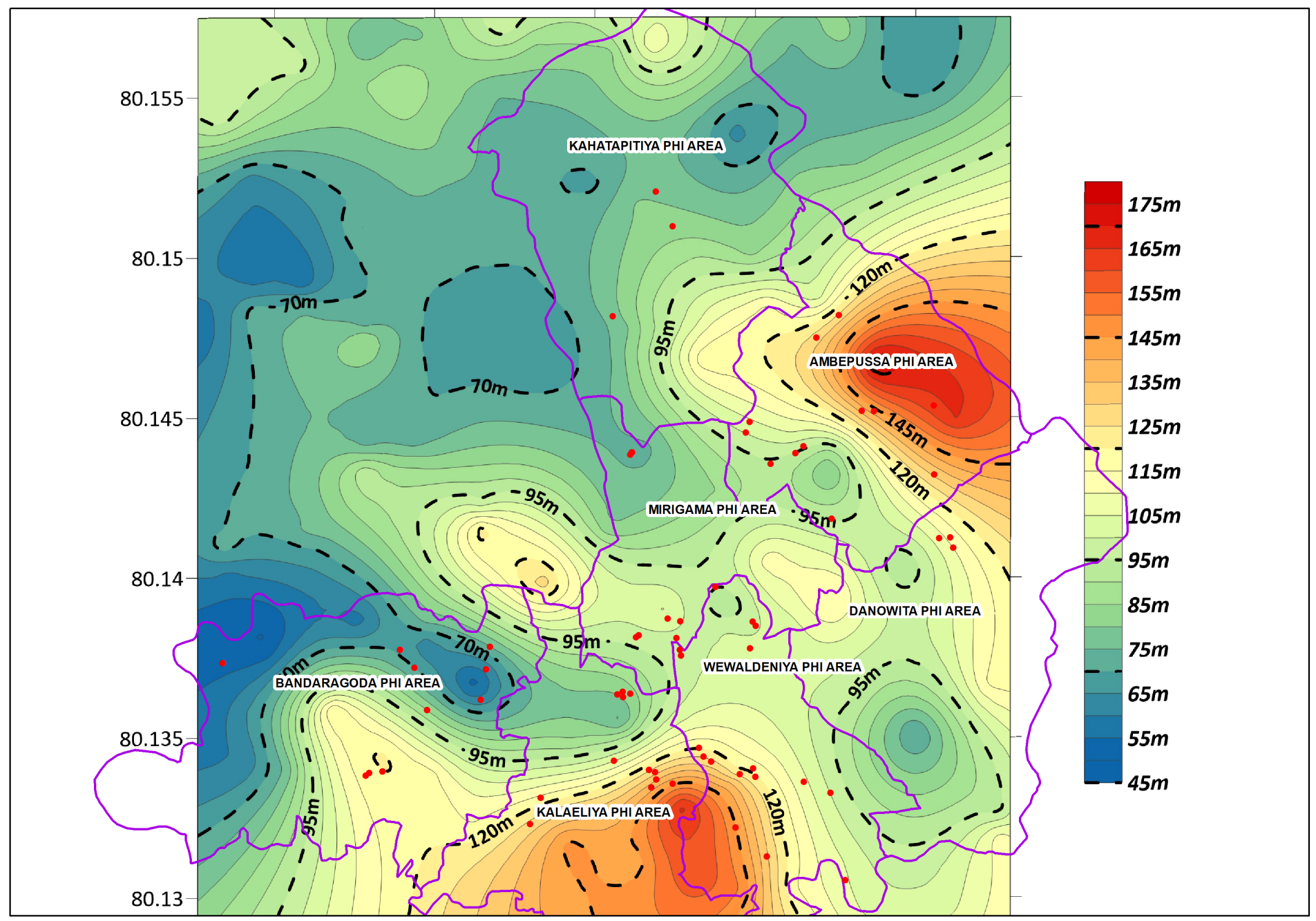

Figure 2

Topographic map of the study area showing the distribution of cases in $\mathrm{MOH}$ area Mirigama

\section{Supplementary Files}

This is a list of supplementary files associated with this preprint. Click to download.

- Graphicalabstract.pdf 